\title{
The breaking of the spell. Young women and internships in popular television culture.
}

\begin{abstract}
This article is concerned with the popular imaginaries associated with internships and unpaid labour and their implications for emerging subjectivities and conceptualisations of work. It draws on a comparative analysis of three prime-time television series about young women's experiences of their first entry in the world or work. By analysing the articulation of power relations between characters, and the imaginaries of work and success mobilised, the three series under examination, The Carries Diaries, Girls and 2 Broke Girls, all reveal a normalisation of internships as a rite of passage for educated young women to enter the world of professional employment, articulated through different approaches to the issues of pedagogical, gender and labour relations. Their pre-emptive inherent critique of the official dual promise of internships as a learning experience and as a step towards paid employment is analysed in relation to recent critical attempts to counter-representations and free labour organising.
\end{abstract}

Keywords: internship, unpaid labour, popular culture, TV series, young women.

Valeria Graziano is a $\mathrm{PhD}$ candidate in the School of Business and Management and the Drama Department at Queen Mary University London. Her thesis investigates the notion of conviviality across artistic practices, militant organizing and collective learning. With the collective Micropolitics Research Group (UK), she contributed to a number of participatory action research projects on the conditions of collective individuation and circulation of value in post-Fordist societies. In recent years, she co-curated Summer Drafts - Laboratories of Transversal Vivacity, an experimental programme exploring pedagogies of anti-racism in the province of Bolzano (IT) and, with colleagues at the Centre for Ethics and Politics (UK), she initiated the practice exchange series Self.Organizing.

Dr Mara Ferreri is a teaching assistant in the School of Geography at Queen Mary University London. Her thesis 'Occupying vacant spaces: precarious politics of temporary reuse' discusses the conditions and potentialities of temporary self-organised and cultural urban projects.

In the context of emergent forms of free and unpaid labour, internships have rapidly gained centre stage as an example of work precariousness that presents emerging processes of subjectivation. From a marginal phenomenon linked to specific professions or educational patterns, they have quickly progressed to becoming the standard way of entry into the labour market internationally. The official international narrative about internships can be traced back to the Bologna process and combines a reformulation of the relationship between institutions of further and higher education and the job market. According to the official discourse promoted by policy-makers, universities and private sector, internships present a dual character: as a process of education (pedagogical dimension) and as a step leading to professional employment (labour dimension). The pedagogical and the labour dimensions indicate the two promises offered to students and graduates as a reward for their unpaid and free labour: on the one hand, that the internship will complement their formal education by offering necessary skills and providing professional experience, on the other, that it will offer an entry to the professional market place and, if successful, a paid position.

The present article wishes to trace the representation of internships as an emerging narrative device prime time television series, and particularly programmes representing and targeting young women. More specifically, the present study focuses on three popular sitcoms: The Carrie Diaries (The CW, USA: 2013), Girls (HBO, USA: 2012) and 2 Broke 
Girls (CBS, USA: 2011). All three are widely popular series produced in the US within the last two years and are currently being broadcasted by a range of cable and satellite TV channels across the globe. The three shows present similar characteristics, as they focus on young women's experiences of first employment in New York, a city that is represented as a key site for professional and personal emancipation. All protagonists experience internships in the context of emerging creative professions: publishing/books fiction writing, fashion/journalism, and a cupcake start-up company catering to the urbanite creative class. In all three instances internships are introduced as a matter-of-fact rite of passage for young women. While each plots does not revolve around the internship nor around questions of labour per se, internships are key ingredients in the development of the main characters and are central to broader narratives of professional success and individual subjectivation. Despite the similarities however, each series presents a different imaginary about work and attributes a different significance to the moment of internships, revealing a spectrum of positions vis-avis the experience of interning and subjectivation that offers insights for the investigation of gender norms in the context of work and generational precarity.

This article offers a close comparative reading of selected scenes from each of the three TV series, in order to highlight the nuances and fine-grained characteristics of contemporary popular representations of unpaid internships. Television is "part of our fantasy structure" (Miller, 2010 p.2) and provides "stories which dramatize society's values, ideals and ways of life"(Douglas Kellner (1982) in ibid, p.84), which often have the great influence on adolescents' and young adults' perceptions and understandings of work (Heintz-Knowles, 2000; Lury, 2001; Blake-Beard and Morgan Roberts, 2004). Moreover, with the deepening of the credit crisis and ensuing recession in many Western countries, TV ratings have shown a distinct statistical increase and potentially a greater influence (Miller, 2010 pp13-14).

By addressing popular culture as a site of "innovative, insightful and penetrating critical commentaries on work and organizations" (Rhodes and Westwood, 2008, p.2), this article analyses key scenes and dialogues from the three TV series to highlight-wider issues concerning pedagogical, labour and gender processes of subjectivation. Moving from representations to lived experiences, it will propose that the themes identified find resonance in young women's accounts of internships in the creative and cultural sector, offering insights into the production of young workers' subjectivities as a historic and cultural shift post-2008 crisis In the conclusion, the insights offered by each reading will inform a reflection on the mainstream critique of the official narrative of internships outlines in the introduction, and its implication for campaigning and for wider debates on free and unpaid labour.

\section{The Carrie Diaries or the internships as an enchanted fable}

The Carrie Diaries is an American teen drama television series on The CW, a television network programming mainly for young women. It is based on the novels "The Carrie Diaries" and "Summer and the City" by Candace Bushnell, and it is promoted as a prequel to the HBO television series Sex and the City (HBO, USA: 1998) the extremely influential television series that run from 1998 to 2004, by the same author. The show focuses on the teenage years of Carrie Bradshaw, the fashion columnist and central heroine of Sex and the City (SatC) and is set in a fictional 1984, when Carrie is a teenager living at home in a small town in Connecticut. During her junior year, her father makes an agreement with the school allowing Carrie to intern for a Manhattan law firm once a week. While in Manhattan, however, Carrie will meet the world of fashion journalism and start her career.

The significance of producing a teen series that is cast as a prequel to $S a t C$, targeting a younger audience than the original show, is revealed in the role assigned to the internship as a rite of passage marked by positive experience. In SatC Carrie Bradshaw is the epitome of professional and personal success. By putting an internship as the magical first step in that direction, The Carrie's Diaries reproduces the myth of internships as an opportunity and stepping stone in the development not only of a professional career, but as her adult subjectivity as an emancipated and sophisticated urban woman. It is important to note that in 
the original novels Carrie's career begins with a summer writing programme at the New School, and the internship was only introduced in the TV adaptation.

The key narrative device to introduce Carrie to the exciting urban experiences promised by the world of fashion is an internship gained through a chance encounter with Larissa, the stylish and eccentric editor of the fictional fashion magazine Interview. The woman, soon to become her boss, notices a customized purse the girl has created and wants it for a fashion photo-shoot. Impressed by Carrie's natural 'talent' and good taste in fashion, Larissa offers her an internship at the magazine as a reward.

The trope of interning as a magical experience is set during the scene in which Larissa offers the internship to Carrie while at the same time encouraging her to become a writer:

Larissa: You've got a real knack for this, Carrie Bradshaw [...] Come and work for me at Interview.

\section{Excuse me?!}

L: You would fit right in. First you come up with this brilliant purse, then you spice it up with an equally brilliant caption; you inspired my next photo shoot. You would be fantastic! (Series 1, Episode 5)

During the internship Carrie is presented as full of talents that she does not know she has yet, and the role of her mentor Larissa and of the other co-workers is to help her to become aware of her own potential. Praise, reassurance and compliments abound in all dialogues as Carrie is depicted as coming up with brilliant ideas at the right time, effortlessly solving problems and inspiring others (for instance, Series 1, Episode 7 "Caught"). Larissa confirms this by constantly complimenting Carrie: "Genius!"; "You saved me!"; "You're bri-zilliant!"; Perfection! "You are saving my life!" are recurring exclamations in the interactions between the two characters.

As a typical teen drama Carrie's life is divided between love, troubles and dreams about her future life, but as the internship progresses, however, the career aspirations explicitly take over the romantic desires of the protagonist. Through a series of direct references to the fable of Cinderella, the experience of the internship replaces the normative teen-drama wish of meeting Prince Charming. In the same episode cited above, for instance, Carrie is ready to go to the school dance wearing a glittering princess-like dress, but her voice over fantasies are not about her teenage boyfriend awaiting her, but about accessing the dream world of Interview. Parallels with the fable are enforced by the voice over during an episode in which she is encouraged to wear a pair of beautiful designer shoes to join her work colleagues at a glamorous Manhattan club, the contemporary equivalent of a princess' ball (Series 1, Episode 8).

In keeping with the Cinderella simile, the workplace is often described as a dream and the fact that it is unpaid is overlooked since Carrie is not 'getting a job' but embracing a lifestyle, as exclaimed by her teenage best friend: "Think of all the parties you'll get to go to, all the celebrities you'll get to meet, all the clothes you'll get to wear!" Before the start of the internship Carrie affirms: "I imagine the Interview offices are less like work and more like a giant playground!" and her experience will confirm no discrepancy between expectation and reality as on top of avoiding a pedagogical teacher to pupil relationship, the script also avoids to come to terms with the power dynamics between boss and employee. While internships are represented in the official narrative as moments of training or education, Carrie's relationship with Larissa is not one of mentorship, but one of enchanted collaboration and friendship. Carrie is given recognition and responsibilities, but she is never asked to learn new skills or tasks. The girl seems to already possess all the fresh qualities that the magazine needs, and all that Larissa teaches her is how to valorise her qualities and sell her talents. Contrary to popular representations of the passage between a carefree high school and the difficult reality of entering the labour market, in Carrie's interning experience all relations are smooth, 
playful and glamorous, while all her conflicts and difficult negotiations happen elsewhere, in more traditional institutions such as at school or at home.

\section{Girls and Hannah's coming of age}

Created by and starring Lena Dunham, and supposedly drawing on her own real-life experiences, Girls is a comedy-drama that was premiered on HBO on $15^{\text {th }}$ April 2012. As in The Carries Diaries, this series too positions itself in explicit reference to Sex and the City as the author has stated on many occasions that she wanted Girls to portray a part of the female population excluded from the $1998 \mathrm{HBO}$ series. Its reception has been extremely favourable worldwide and the series has received numerous awards in the US and the UK. The plot follows the lives of a close group of four twenty-something girls living and working in New York City, and the theme of internship is introduced in the very opening scene of the first episode of the series. Hannah, a young literature graduate and aspiring writer, is having dinner with her parents who are visiting her in NYC. While at first the dialogue leads the spectators to believe that the girl has a promising career in the publishing industry, during the course of the dinner, it is revealed that her 'work' is actually a long unpaid internship. When Hannah's parents tell her that they will no longer support her financially, Hannah pleads with them stating that all of her friends are receiving financial help from their families in order to survive in NYC. To her claim that she should be entitled to receive money because "I am busy trying to become who I am", her parents respond by accusing her of expecting them to "bankroll" her "groovy lifestyle".

Hannah's ensuing confrontation with her boss Alistair to receive payment for her work is worth quoting at length, as it includes a complex spectrum of rhetorical strategies used to justify the practice of unpaid labour:

Hannah: As you know, I've been working here for over a year...

Alistair: Has it been that long? Well, you are an invaluable part of our operation...

$\mathrm{H}$ : Which I recently learned means very valuable as opposed to not at all valuable. And I wanted to let you know that my circumstances have changed and I cannot longer afford to work for free.

A: Oh, Hannah...I'm...I'm so sorry to lose you. I was just gonna start you manning our twitter, you have just the quippy voice for that...

H: Oh, no, no, I'm not quitting, I'm just, hem...I know that, [lowers voice] Joyleen got hired after interning, so I thought that maybe...

A: Yeah...Joyleen knows Photoshop. Now, in this economy, do you know how many internship requests I get every day?

H: I would assume a lot...

A: Fifty, it's about fifty. I practically route them into my spam folder. So, if you think you have just nothing left to learn from us...

H: No, it is not that, really, it's just, you know, I gotta eat...

A: [Smiles knowingly] Well, when you get hungry enough, you gonna figure it out.

H: Do you mean like physically hungry or like hungry for the job? 
A: [Serious, then smiles again and says]: I'm really gonna miss your energy. I think this is gonna be really good for you. [Alistair gets up, leans towards Hannah, shakes her hand and hugs her].

H: Ah...You mentioned that when I was gonna be finished with my book I could send it to you...

A: Well, we would not have you here to read it for us, would we? (Series 1, Episode 1)

This dialogue brings together many of the key themes related to the representation of internships. Hannah's boss goes through a range of rhetorical operations revealing the power relations at play between the two characters. First he flatters her by offering recognition in exchange for her labour. Then he expresses regret at losing her and pretends that he was just about to give her better - that is, more creative and requiring a personal touch responsibilities as part of her workload. Responsibility (the opportunity to prove yourself professionally) and self-expression (creativity) being the key alternative promises of the pedagogy of internships in lack of a real job offer at the end. When Hannah mentions Joyleen, another intern who had been offered a paid position, Alistair explains that the other girl possesses technical abilities that Hannah is lacking. Here, the previous underlying argument about self-expression is contradicted by the actual demand for proficiency in technical tasks rather than unique personality traits.

Following that, there is first a reference to the state of the economy, immediately followed by a more direct hint to the number of requests for unpaid internships received by the firm. Here the rhetoric switches from the initial encouraging tone to a more menacing one, referring to a classical menace to the employed workforce (Marx's 'reserve army of labour') and to the more recent discourse of crisis capitalism. From offering symbolic compensations, the boss progresses to accuse Hannah of being arrogant and ungrateful, suggesting that she wants to quit because she feels she has nothing left to learn from the firm, something the girl never suggested in the first place. He suggests that Hannah is not 'hungry' enough yet, insinuating a lack of commitment and character in the girl. As the scene comes to a close, we see the boss turning the tables on Hannah one last time as he responds with derision and scorn to Hannah's final attempt to keep open the possibility of maintaining a professional relationship. Despite the fact that Hannah's character is generally presented as articulate, opinionated and assertive, during this scene she is shown as naive in her expectations and unable to react to the situation.

\section{Broke Girls and the question of class}

Finally, a more nuanced and ambivalent representation of internship is offered by the last case study of the present analysis, 2 Broke Girls. The sitcom debuted on CBS in September 2011 and was nominated for three Emmy Awards in 2012. The series' premiere was watched by over 21.5 million viewers in the US, a record result, and has been broadcasted since in over 40 countries worldwide. The comedy revolves around two young women, Max and Caroline, who work as waitresses at a diner in Brooklyn, New York. While Max comes from a working class background, Caroline is the daughter of a former millionaire who was imprisoned for financial crimes during the credit crisis and whose family assets were frozen. The two girls share the dream to start a cupcake business in NYC and the main plot revolves around their efforts to find the money for launching their business.

Here, the theme of internships is addressed in just one episode (Series 2, Episode 9), when Max and Caroline finally manage to rent a shop, but are faced with a pest infestation and major redecorating work. Caroline, who is cast as the entrepreneurial personality of the duo, enthusiastically proposes to find an intern as a solution to their chronic condition of overwork: 
Caroline: So, my brilliant ideas of how we get this all done is we should get an intern to help...

Max: What?! No! I can't be a person who has an intern. I can barely be a person who doesn't have an intern...

C: Max, all businesses use interns! We just have to post an ad online, at NYU or Columbia and we'll have twenty applicants battling it out to do our groundwork for credits...

M: You make it sound like the Hunger Games College Edition... Sorry, I am against getting people to work for free...

The exchange reveals the different attitudes to paid and unpaid work, which parallel the class difference between the two girls. The normalisation of unpaid internship for middle-class people, and the connection with higher education at elite universities such as NYU and Columbia, clashes with a working-class resistance to work for free epitomised by Max's remarks who is surprised to discover that the intern owns a car - a detail that reveals the comic paradox that someone who chooses to work for free is someone who does not have to work. In the same scene, the contrasting perceptions of internships informed by the different class status of the girls is also reinforced by the comments of Earl, the African American cashier at the diner where the girls work, who humorously declares: "I'm with you Max. My people were interns for 436 years..." - equating internships to slavery.

Another peculiarity of the representation of internships in this series concerns the pedagogical aspect. While in The Carries Diaries and Girls this dimension is not explicitly addressed (Carrie as natural talent, Hannah is confronted with an utterly cynical boss), in 2 Broke Girls the internship is an important moment of learning, but the learning process is shifted from the intern, Ruth, to the 'girls', as Caroline uses the internship to teach Max how to become a boss:

Caroline: There. Go open the door. You know it needs to happen. [To her boyfriend] Max has to learn how to put Ruth in her place so she can learn how to be a boss.

Max: I am not supposed to fire someone, I am the someone who's supposed to be fired...

While there are no references to Ruth (the intern) learning anything at all from the girls, Caroline insists on pushing Max to embrace the opportunity of being on the opposite pole of the relationship of subjection, a power over, that she is used to. Given that one of the series' main myths is that of entrepreneurship as a path of emancipation from poverty and from the condition of being employed, this episode interestingly undermines this claim by showing that actually to become self-employed means to become an employer, not to break free from power relations, but to simply shift positions within the same framework. While Max is resistant to this trajectory having occupied the subordinate labour position for a long time, Caroline seems to never question the principle of hierarchy, and she is the mentor that trains Max in becoming a sadist boss. The representation of the intern as lazy, cunning and solely motivated by the need to gain university credit for her degree, further unmasks the pedagogical narrative and reveals its empty opportunistic nature.

\section{From enchantment to cynicism}

In the prequel to $S a t C$, Carrie is successful not because of her hard-work or her learning curve, but by virtue of a perfect magical fit, reproducing ideas of talents to be discovered rather than of skills to be learnt or developed. She is successful in virtue of who she is, not of what she does. Girls' Hannah, on the contrary, is naïve and infantile. The end of her 
internship is the beginning of the series and her adventures in NYC, yet the unveiling of the false promises that bound her to unpaid employment did not correspond to any form of resistance or solidarity or a transformation of her desire for recognition and professional career. Her desired success as a writer is still highly individualistic, as is her experience of failure. Finally, in the case of Max and Caroline, while they position themselves as bosses, replicating the imagined normative power relations between intern and manager in the work place, they embody the (failed) entrepreneurial subject. Their attempt to escape the reality of the diner by creating their own dream of success ends up uncritically reproducing forms of exploitation - and Max's attempts at establishing forms of solidarity with Ruth are finally resolved when her character 'learns' how to fire the intern.

The shared topics of self-expression, of urban living and the passage to independent womanhood have already been discussed by feminist sociologists in connection to Sex and the City (Arthurs 2003; Akass and McCabe 2004) as a post-feminist imaginary (Faludi 1991; McRobbie 2008), in which feminist gains and values are re-appropriated by dominant discourse in such a way as to foreclose their potential systemic critique. However, in place of the promises of the official discourse of internships the three series under exam all bring to the surface the new post-SatC anxieties of young women entering the world of work. In The Carrie Diaries, even if the audience already knows that Carrie will become a successful writer, the fairy tale narrative points at the very anxieties it aims to neutralize: the fear of a meaningless occupation, of a life away from the big city and its glamorous networks. Despite the different narrative register, for Hanna too the dream of success is cast in terms of personal expression, not in terms of learning or of work understood as a mean to an end. Lastly, in 2 Broke Girls the disengagement of the intern from her own process of learning or finding a job are brought to clash with the rhetoric of entrepreneurialism that the two protagonists use to frame their own experience of precarity.

Drawing on the themes identified in the current positive and negative representation of interns in popular television culture it is possible to advance two sets of hypotheses concerning the implications of these narratives for the lived experiences of young interns and for political organising. First, the narratives proposed by each of the three series selected for our case study appears to correspond to a distinct 'phase' in the life narrative and selfperception of young women in relation to their job expectation: from enchantment (The Carrie's Diaries) to the breaking of the spell (Girls) and finally to disillusioned and cynical opportunism (2 Broke Girls). Participatory action-research conducted with students and young workers in the creative sectors in the UK between 2005 and 2012 confirm this hypothesis. As explained by one interviewee, a young woman in her early 20 s, thinking back to her first internship in a public art gallery:

At the beginning I didn't know anything about the admin and kind of mundane work that goes on behind the façade. I imagined that all [workers] would be involved in some creative job or other, that we'd all be part of the glam and the buzz. When I got [the internship] I thought they valued my background, my ideas and my personality...not my data entry skills! (Interview with M, 2007)

Students and young workers who never had an actual experience of internship, or who were just at the beginning stages of one, tended to describe their expectation in terms of a chance to prove their talent. As many interns are assigned routine jobs unrelated to their skills and education, however, they begin to question the enchanted fable of recognition and the path to success:

I thought that any experience in the field would be good experience. The task that I was allocated when I arrived at my internship however was to organize the gallery's accounts, the whole of the gallery's accounts...It's funny, because my educational background was in Art History and Literature (Carrot Workers, 2009, p.30) 
Following the experience of one or several internships, and sharing frustrations among peers, it is possible to identify a third phase in the development of self-narratives as young workers discover that precarity is systemic, and that survival is dependent upon tactical cynicism more than on passion or talent. As explained by $\mathrm{J}$, a visual arts graduate with three internships under her belt,

in my last internship I made sure I played it right... I put my address on the gallery's VIP list, so I got the invites to all the private openings, ah ah! I showed up at every single event, chatted around. Made sure that those who count remembered my name. That's really the only thing I learnt from this (Interview with J, 2011)

\section{Imagining and organising}

The second hypothesis emerging from the comparison between popular imaginaries and experiences on the ground concerns the possibility of critical organising around the issue of unpaid labour. In the decade preceding the three television series, the first attempts to engage with the issue of internships were formulated as a critique, both in academic discourse (Terranova, 2000; Graeber, 2005) and public debate (Perlin, 2011; Howker and Malik, 2010; Carrot Workers Collective, 2009), as part of a wider discussion around the increasing precarisation of labour and life (Berardi, 2009). That decade witnessed the proliferation of campaigning groups and online platforms opposing unpaid labour and the insertion of internships as compulsory parts of the curriculum in various countries: Stage Critics (since 2001) and Generation Precaire (since 2005) in France; The Carrot Workers Collective/Precarious Workers Brigade (since 2007), Intern Anonymous (2009) and Intern Aware in the UK; Chainworkers (since 1999) and Repubblica degli Stagisti (since 2008) in Italy; Unfair Internships (since 2006) in the USA.

Many if not most of these collectives and campaigns actively produced counterrepresentations of free labour as part of their critique of the political and economic situation. For instance, Generation Precaire used a white mask to remark the disposability and replaceability of interns. Chainworkers issued a set of precarious tarots featuring The Intern as one of the deck's figures, substituting the rhetoric of constant self-perfecting and meritocracy advocated by neoliberal discourse to justify precarisation with that of chance and luck. The Carrot Workers Collective has been mobilizing the symbol of the carrot to deconstruct the dynamic of reward and punishment (stick) that characterises relations of job placements in the cultural sector. Even more significantly, this group has been facilitating workshop on the theme of internship inviting participants to produce photo-romances focused on their own experiences of working for free in the creative sector. These counter-representations of internships have helped to raise the hitherto low profile of unpaid and lowly paid internships in mainstream media and to facilitate a public debate over it implications both as a barrier to a democratic access to professions and as the erosion of existing workers' rights.

With the introduction of internships as a compulsory element in higher education, and with the shrinking economy resulting from the 2008 crisis, the experiences of young creative graduates entering the job market has radically shifted as enchantment and disenchantment give way to disillusion, not just with the personal experience but with the sector more broadly, as explained by a third-year curating female student:

Everybody knows that internships suck. ... Everyone in London knows that, but still, I mean, there's no real jobs around, with the crisis and all, and they always ask for donkey years of experience anyway - so, it's the only way we have to get in. That, or give up (Interview with $\mathrm{K}, 2011$ )

As discussed by a member of the Carrot Workers Collective, the terrain of representation as a focal point in the constitution of collective organising against unpaid internships is increasingly inadequate to the task: 
In the first years, whenever we brought up the question of free labour and unpaid internships in discussions with young people, they got angry or didn't understand. They had never thought of themselves as workers. They wanted to be individuals, artists. They did not want to think about what they did as work... but in the last five years, whenever we held seminars or workshops, and not only in the UK, but also in other places like Ireland, Poland or Italy, they are less surprised, they already have a good analysis of what is going on, but they seem resigned and also a bit cynical, as if they accepted internships as an inevitable evil (December 2012)

The juxtaposition of mainstream and critical representations of internships reveals an element missing in both: the articulation of alternative imaginaries of the pedagogical moments that exist in the blurring of work and education, capable to deal with the same anxieties emerging from the series. The internship can be seen as a signpost for not just a temporal phase, but as a space between - a complicated space to conceptualize and mobilise around - higher education and the world of work. Vis-à-vis the normalisation of the critique of internships and unpaid labour in popular culture, the issue of elaborating alternative imaginaries emerges as the new challenge posed to activist and cultural practitioners organizing around issues of free an unpaid labour. It moreover challenges the stance of recent research on issues of unpaid internships aiming to 'uncover' conditions and experiences something about the imaginary of victimhood no longer mobilises outrage. Now that the critique of free labour seems perfectly integrated in the thematics offered in popular culture, one of the focuses of labour organising might need to shift from critique to production of different imaginaries of self-realisation.

\section{References}

Akass, K., \& McCabe, J. (Eds.) (2004). Reading Sex and the City. IB Tauris Publishers.

Arthurs, J. (2003). Sex and the City and consumer culture: Remediating postfeminist drama. Feminist Media Studies, 3(1), 83-98. DOI:10.1080/1468077032000080149

Berardi, F. (2009) The soul at work: From alienation to autonomy, trans. F. Cadel and G. Mecchia. New York: Semiotext(e).

Blake-Beard, S. and Morgan Roberts, L. (2004) Releasing the Double Bind of Visibility for Minorities in the Workplace, Center for Gender in Organization.

Carrot Workers Collective (2009) Free Labour, Enforced Education and Precarity: an initial reflection, reprinted On Curating, 16/13: 22-25; text also available at http://carrotworkers.wordpress.com/on-free-labour/

Faludi, S. (1991) Backlash: The Undeclared War Against Women, New York, Crown.

Graeber, D. (2005), Value as the Importance of Actions, The Commoner, 10.

Heintz-Knowles, K. E. (2000) Images of youth: A content analysis of adolescents in prime-time entertainment programming, paper prepared for the Frameworks Institute, text available online

at http://www.frameworksinstitute.org/assets/files/PDF/youth_content_primetime.pdf

Howker, E. and Malik, S. (2010) Jilted Generation: How Britain Has Bankrupted Its Youth. Icon Books. 
Lury, K. (2001) British Youth Television: Cynicism and Enchantment, Oxford: Oxford University Press.

Miller, T. (2010), Television Studies, London, Routledge.

McRobbie, A. (2008) The Aftermath of Feminism: Gender, Culture and Social Change, London, Sage.

Perlin, R. (2012) Intern Nation: How to Earn Nothing and Learn Little in the Brave New Economy. Verso Books.

Rhodes, C. and Westwood, R.I. (2008) Critical Representations of Work And Organization in Popular Culture, London, Routledge.

Terranova, T. (2000) 'Free labor: Producing culture for the digital economy', Social Text, 18(2): 33-58. 